\title{
A STUDY ON FIRE SPREADING MODEL FOR THE SAFETY DISTANCE BETWEEN THE NEIGHBORHOOD OCCUPANCIES AND HISTORICAL BUILDINGS IN TAIWAN
}

\author{
CHIA-HSIN CHEN $^{\mathrm{a} *}$, SHEN-WEN CHIEN $^{\mathrm{b}}$, MING-CHIN HO $^{\mathrm{c}}$ \\ ${ }^{\text {a }}$ Graduate Student, Department of Fire Science Central Police University, Taoyuan, Taiwan - carriemialy@ gmail.com \\ ${ }^{\mathrm{b}}$ Professor, Department of Fire Science Central Police University, Taoyuan, Taiwan - una179@gmail.com \\ ${ }^{c}$ Director, Architecture and Building Research Institute, Ministry of the Interior, Taipei, Taiwan -ho@abri.gov.tw
}

KEY WORDS: Fire Dynamics Simulator (FDS), fire load, fire spread model, historical buildings, safety distance

\begin{abstract}
Cultural heritages and historical buildings are vulnerable against severe threats from fire. Since the 1970s, ten fire-spread events involving historic buildings have occurred in Taiwan, affecting a total of 132 nearby buildings. Developed under the influence of traditional Taiwanese culture, historic buildings in Taiwan are often built using non-fire resistant brick-wood structure and located in proximity to residential occupancies. Fire outbreak in these types of neighborhood will lead to severe damage of antiquities, leaving only unrecoverable historical imagery. This study is aimed to investigate the minimal safety distance required between a historical building and its surroundings in order to reduce the risk of external fire.

This study is based on literature analysis and the fire spread model using a Fire Dynamics Simulator. The selected target is Jingmei Temple in Taipei City. This study explored local geography to identify patterns behind historical buildings distribution. In the past, risk reduction engineering for cultural heritages and historical buildings focused mainly on fire equipment and the available personnel with emergency response ability, and little attention was given to external fire risks and the affected damage. Through discussions on the required safety distance, this research provides guidelines for the following items: management of neighborhoods with historical buildings and consultation between the protection of cultural heritages and disaster prevention, reducing the frequency and extent of fire damages, and preserving cultural resource.
\end{abstract}

\section{INTRODUCTION}

\subsection{Potential Fire Risk}

According to the Natural Hazard Risks-Absolute Economic Exposure Index, reported by Verisk Maplecroft in 2014-Taiwan ranks the 3rd in global, facing the highest total financial costs from natural hazards. Potential risks are not only from natural, such as typhoons, flooding, earthquakes, fires and biological damages, but also due to human activities.

Around the world, cultural heritages and historical buildings suffered from different levels of natural threats. For example, in 2011, Ayutthaya in Thailand was damaged by flood, 815 people's life lost, most of heritages soaking in flood, and a total 45700 million dollars cost for reconstruction. In addition, the tsunami and post-earthquake fire, following Great East Japan Earthquake in 2011, caused a lot of casualties and property damages. Moreover, in 2014, the fire bursting out through ancient city Dukezong, Shangri-La County of the Tibetan Area in China's Yunnan Province, destroyed more than 250 wooden houses and spread continuously 10 hours. The above-mentioned disasters compose the main threats to the existence of cultural heritages and historical buildings.

In Taiwan, on the other hand, cultural heritages and historical buildings not only suffered natural disasters' attack, such as 921 earthquake in 1999 and Typhoon Morakot in 2008, but also face severe threats from fire. According to the statistics of fire occurrence, 52 fire events happened in Taiwan's cultural heritages and historical buildings from the 1970s to 2014. Among them, the highest proportion of fire causes is arson
(33\%) and the second largest is electrical fire (27\%), as shown in Figure 1.

The cases of fires in Taiwan's Cultural buildings (1970s-2014)

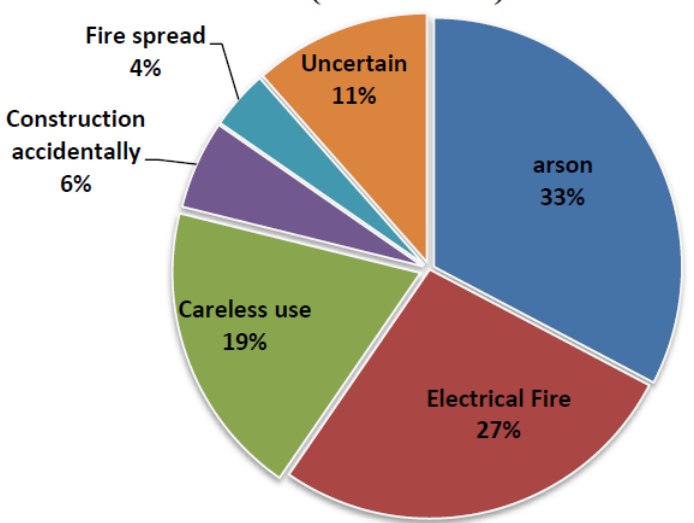

Figure1. The causes of fires happened in Taiwan's cultural heritages and historical buildings from the 1970s to 2014.

Moreover, a further analysis of the fire cases (shown in Table 1) found that, since the 1970s, 10 fire-spread events involving historic buildings have occurred in Taiwan, affecting a total of 132 nearby buildings. Because the cultural heritages are usually located in proximity to residential occupancies, which are built in flammable brick-wood structure, fire outbreaks in these types of neighborhood could spread quickly,

* Corresponding author 
leaving only unrecoverable historical imagery. The threat of fire, especially in the local fire spread cases, to cultural heritages and historical buildings are enormous; therefore, more attention should be paid to disaster prevention.

Table1. The events of the fire spread in Taiwan

\begin{tabular}{|c|c|c|c|}
\hline Year & Location & $\begin{array}{l}\text { Affected } \\
\text { buildings } \\
\text { nearby }\end{array}$ & $\begin{array}{l}\text { Cause of } \\
\text { fire }\end{array}$ \\
\hline 1999 & $\begin{array}{lcc}\text { Tsai Jui-yueh } & \text { Dance } \\
\text { Research Institute } & \text {,Taipei }\end{array}$ & 3 & arson \\
\hline 1999 & $\begin{array}{l}\text { Forty-Forty South village, } \\
\text { Taipei }\end{array}$ & 14 & arson \\
\hline 2000 & Futai Street Mansion, Taipei & 2 & $\begin{array}{l}\text { careless } \\
\text { use }\end{array}$ \\
\hline 2001 & $\begin{array}{l}\text { Lintienshan } \\
\text { Forestry,Hualien }\end{array}$ & 35 & $\begin{array}{l}\text { careless } \\
\text { use }\end{array}$ \\
\hline 2002 & $\begin{array}{ll}\text { Hukou old street } \\
\text { description, Hsinchu }\end{array}$ & 7 & $\begin{array}{l}\text { electrical } \\
\text { fire }\end{array}$ \\
\hline 2004 & $\begin{array}{l}\text { Wooden buildings in } \\
\text { Alishan, Chiayi }\end{array}$ & 23 & $\begin{array}{l}\text { Uncertai } \\
\mathrm{n}\end{array}$ \\
\hline 2008 & $\begin{array}{l}\text { No.270.272.274.276.278 in } \\
\text { Dihua Street,Taipei }\end{array}$ & 5 & $\begin{array}{l}\text { electrical } \\
\text { fire }\end{array}$ \\
\hline 2013 & $\begin{array}{l}\text { Japanese-style dormitory in } \\
\text { Shuili township, Nantou }\end{array}$ & 35 & arson \\
\hline 2013 & $\begin{array}{l}\text { Yin Hai-kuang's residence, } \\
\text { Taipei }\end{array}$ & 6 & arson \\
\hline 2014 & $\begin{array}{l}\text { Japanese-style dormitory in } \\
\text { Huwei, Yunlin }\end{array}$ & 2 & arson \\
\hline
\end{tabular}

\subsection{The Structure of the Buildings in Taiwan}

Cultural heritages and historical buildings structures are manifold and rich in Taiwan, because of the cultural background and integration in the past 300 years. Based on the construction timing, they can be classified into the following: Japanese-style in wooden structure, Traditional brick-wood structure, and Western-style in reinforced concrete structure, in which the modern buildings are built.

Since the Japanese-style wooden buildings are vulnerable and flammable, scholars and professionals have researched on fire prevention for a long time. However, little has been done for brick buildings, with brick as main material, red tile roofs, and wooden beams and furniture. In contrast to the common belief that brick is a quasi-fireproof structure that has one-hour anti-fire age, traditional brick construction is actually easy to have gaps and natural deterioration. Therefore, when heated, the wooden beans and carves in stone painting crack and spall.

Yet the traditional brick buildings are the most famous architectural form of temples in Taiwan. Since the development of urban settlements, some vendors and civil house are surrounding temples, forming a special cultural landscape and local specialties. As a result of the complicated use patterns, buildings face severe challenges of risking external fires and spread scenarios.

According to the report of Architecture and Building Research Institute (Jui-Ling Chen et al., 2012), wooden construction constitutes about $67 \%$ of all the cultural heritages and historical buildings in Taiwan. In addition, $36.5 \%$ of the post-fire cases in Taiwan are wooden construction fire and $32.7 \%$ of that are brick construction fire. Therefore, more attentions have to be paid on the fire prevention of brick construction.

\section{CASE STUDY}

\subsection{Fire Spread}

Fire spread is the phenomenon in which fire extends quickly through flame, sparking and radiant heat. The traditional brick constructions are built with wooden interiors: beams, columns, floors, and roof trusses, as well as decoration in doors, windows, partition walls, and furniture. However, the more wooden material a building uses; the more potential fires it risks. Tokyo Fire Department mentioned that once the fire burns out the wooden structure, it expands easily inside the building and ignites flammable items in surrounding.

The research (Wang Song-Yon, 2007) mentioned that fire spread rate is the proportion of expand fire in the happened events. The path of fire spread which not only in wooden structure, but also in other structures through the celling space. Compared with other structures, wooden building has fire spread rate of $67 \%$ and fireproof structure has a high rate of $44.3 \%$, as shown in Table 2.

Table2. Different building aspect have different fire rate

\section{BUILDING ASPECT FIRE SPREAD RATE(\%)}

\begin{tabular}{c|c} 
WOODEN STRUCTURE & $67 \%$ \\
FIREPROOF STRUCTURE & $44.3 \%$ \\
QUASI-FIREPROOF & $44.3 \%$ \\
STRUCTURE & \\
FIRE RESISTANT & $24.2 \%$ \\
OTHER & $50.6 \%$
\end{tabular}

\subsection{Risk Identification}

Risk identification is to verify hazard factors from the cultural heritages and historical surrounding buildings and then take responses and protective measures.

International Training Course (ITC) on disaster risk management of cultural heritage (Rohit Jigyasu, 2014) mentioned 6 key principles of evaluating potential disaster risk in cultural heritages and historical buildings:

1. Assess not only the main and visible factors but also potential hazard factors.

2. Consider the hazards result from the facility interior factors and the environmental surrounding factors.

3. Establish intent relationship between mitigation, preparedness, response, and recovery stage.

4. Establish advanced risk management and assessment program to protect the value of cultural heritages.

5. Use traditional knowledge, engineering and methods to achieve the purpose of mitigation.

6. Connect disaster risk management and preservation maintenance plan tightly in every stage.

Disaster Assessment Technique and Case Study for Taiwan's Heritage (Chien Shen-Wen, 2013) considers risk identification as the first stage of hazard management and proposes a standard of hazard evaluation in order to quantify the potential risks of cultural heritages and historical buildings. It includes hazards due to risks of environments, risks of usage and management, risks of damaging historic building and cultural relics, and risks of evacuation.

Also, Shao Pei-Chun (2010) put forward an integrated fire management strategy, which enhances the environmental fire safety in traditional old urban areas, and performed a comprehensive analysis of the fire risks in Chih Kan Cultural Park: 
1. Traditional wooden buildings have many combustible materials.

2. Fire equipment is not programed and installed completely.

3. The surrounding districts are close to explosive stores, such as firecracker shops and liquefied petroleum gas shops.

4. The buildings in the district, with roof patched with iron sheets and narrow alley, could make rescue activity difficult. 5. Water is in shortage.

In spite of the fact that external and internal factors affect the field of resilience of fire in historic district, the essentials are the ability to prevent and prepare for disaster, the ability to meet an emergency and reduce damage, most importantly, improve the ability to reconstruction.

\subsection{Research Methodology}

Among various approaches to evaluate the fire safety, the most recognized tool in the field of cultural buildings is Fire Dynamics Simulator (FDS), which can simulate fires under different parameters and variations. Therefore, it helps decision making through simulation of similar scenarios. For example, in the paper of Fire Safety Analysis on the Historical Heritages with Southern Fukien Style - Example on Tainan Grand Matsu Temple in Taiwan (Shen Tzu-Sheng, 2013), the author simulated two scenarios (electrical fire and arson; $260^{\circ} \mathrm{C}$ was defined as hazard reference value) to observe the impact damage value of $\mathrm{CO}$ concentration, visual rate, radiant heat, and temperature for internal staffs and collections. The result concluded that the closer the distance between the fire and roof, the faster the fire will expand.

\subsection{Internal and External Factors of Fire Risk in Jimei Jiying Temple}

The studied subject in this paper is Jingmei Jiying Temple and its surrounding vendors in Taipei City. In the early period, Jiying Temple was the most important religious center for local residents; its surrounding areas gathering street vendors has gradually formed the famous Jingmei night-market.

The investigated internal factors of fire risk are as follows:

1. Due to the well-known temple, residents and tourists come to worship and burn incense all the day.

2. The temple service introduces lots of electrical equipment, such as lights, air conditioning, as shown in Figure 2.

3. There is only one service staff in the work hours, and the back doors are usually made open to the public.

4. The lacks of attention in the night and faulty management increase the risk of arson.

5. Both sides of the residences are used to store inflammables (Figure 3), which are vulnerable to fire spread from surrounding vendors.
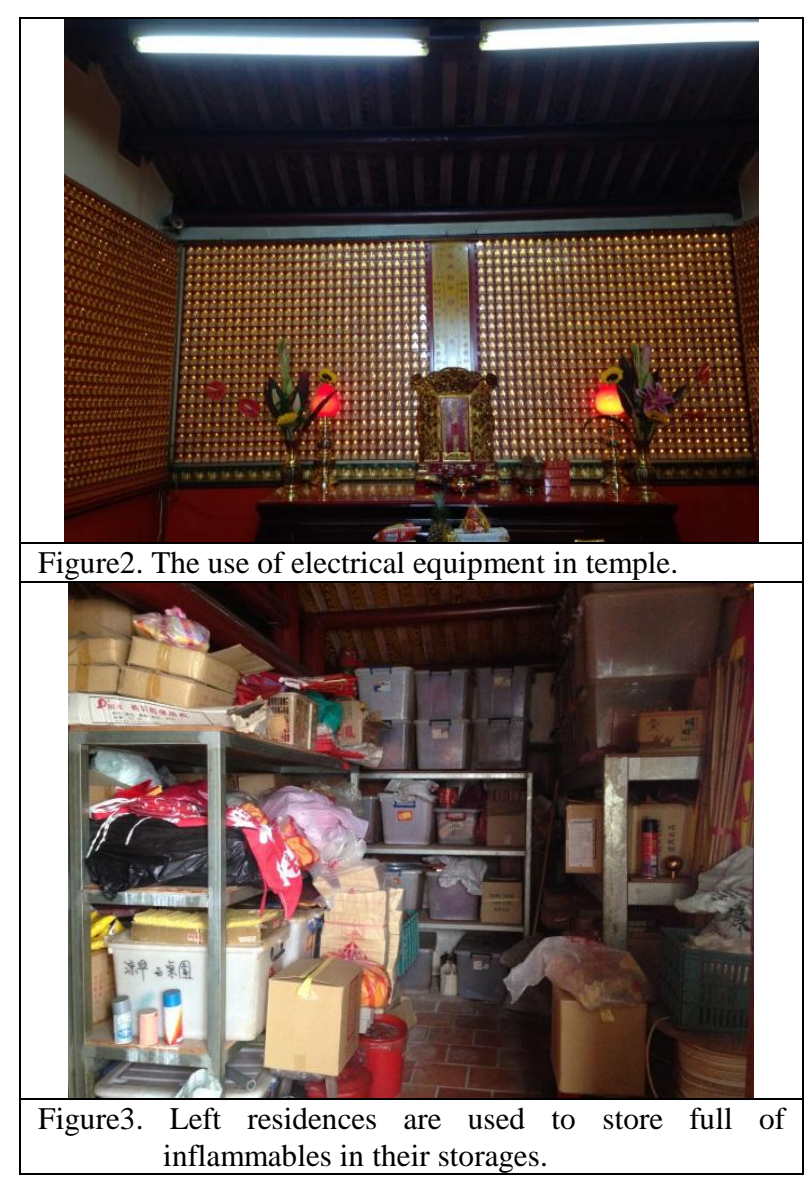

The investigated external factors of fire risk are as follows:

1. The nearby vendors take different usages, e.g. cooking vendors use fire and fuel recurrently, and clothing vendors stack lots of combustibles, as shown in Figure 4.

2. That different vendor renters operate in different hours hamper the promotion of mutual-support group for fire prevention.

3. Relief operations are limited to the narrow alleys, and the canvas above vendors forms a potential path for spread fire.

The internal and external factors of fire risk are showed with ignitions and combustibles in Figure 5.

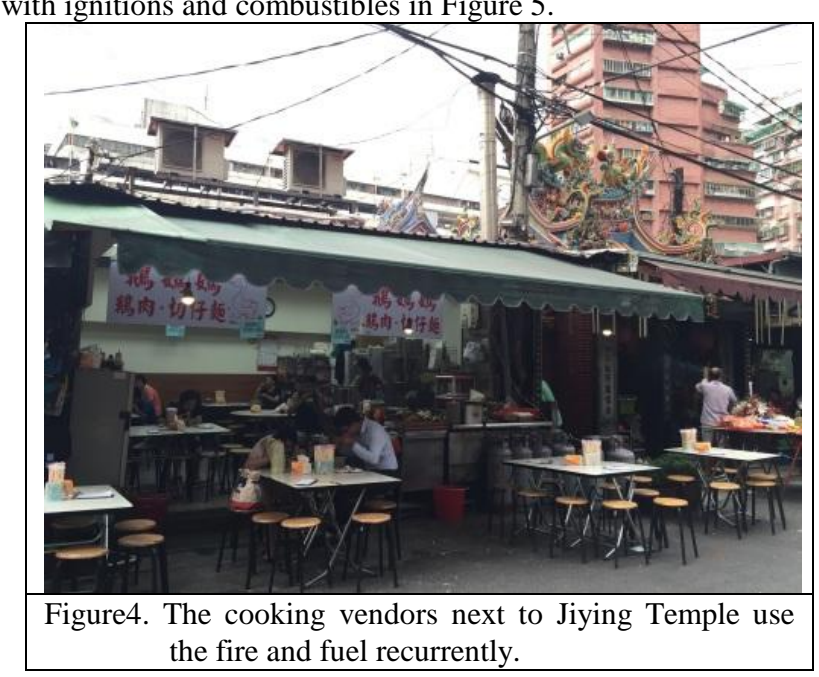




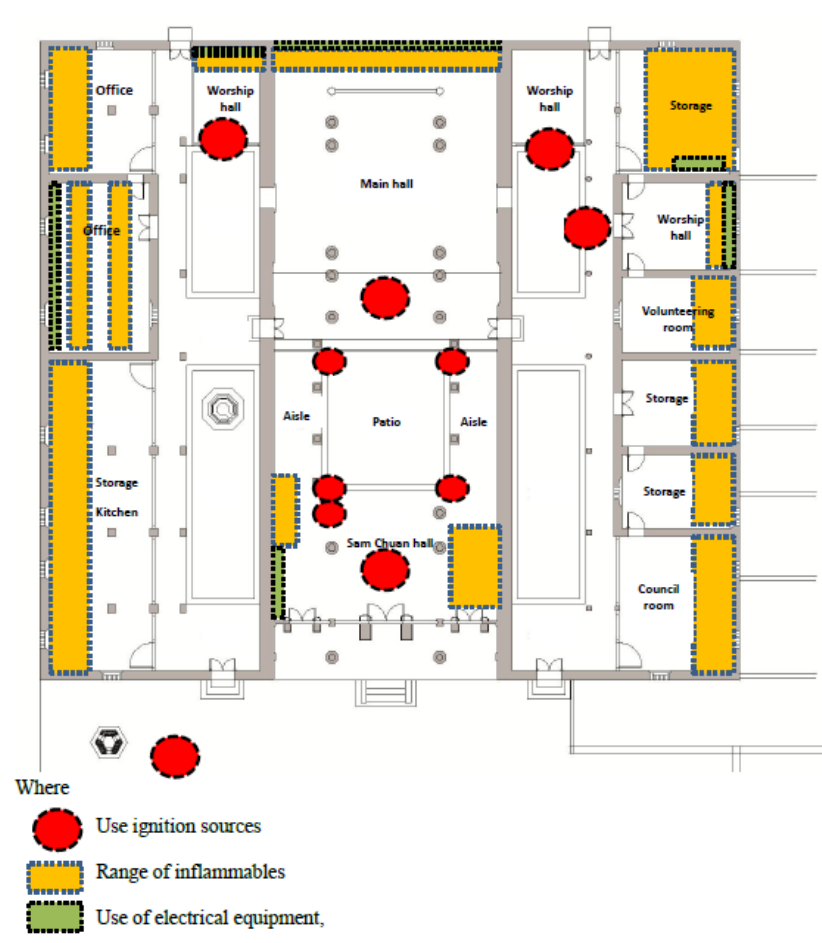

Figure5. The Internal configuration of Jiying Temple that indicated the ignitions and combustibles.

\section{THE FIRE SPREAD MODEL}

\subsection{Design of the Target's Fire Spread Model}

The site survey evaluated and simulated the most possible hazards of Jingmei Jiying Temple. The risk identification shows that both sides of residences stack lots of combustibles. Investigation of environmental hazards also indicated that left residence is close to cooking vendors, which use fuel and fire frequently. Therefore, once fire occurs, sparking and radiant heat would cause expanded fire and damage.

The target of the simulation was the left residence of Jingmei Jiying Temple and its nearby vendors. The simulation range was $30 \mathrm{~m}$ in length, $8 \mathrm{~m}$ in width, and $5 \mathrm{~m}$ in height. The appearance of the fire numerical model is shown in Figure6.

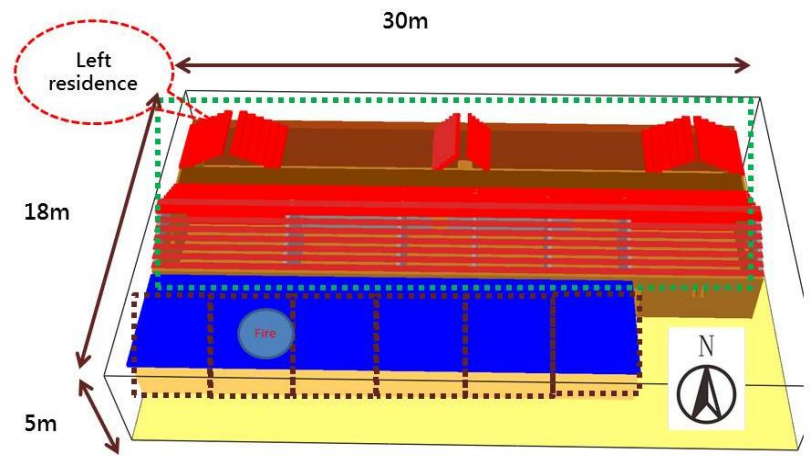

Figure6. The appearance of the fire numerical model

The ignition place was set as the second cooking vendor inside from west, and the fire was located on the wooden table (height $0.8 \mathrm{~m}$ ). The vendors were built by wooden compartment in the interior, and were covered with light gauge steel roof. The simulations assumed midnight fire situation, so the vendors' gates were shut down.

\subsection{Fire Scenarios in Simulation}

The study simulated fire sources with different sizes, in order to investigate external fires starting from different ignition locations, traveling through different paths, and spreading at different rates. Moreover, the safety distance between the temple and vendors was considered. At the beginning stage of the simulation, the fire source size was $1 \mathrm{MWn}$, which set burning rate as heat release rate per unit area (HRRPUA, $\mathrm{kW} / \mathrm{m}^{2}$ ). The time required for the initial ignition to grow was ignored.

According to the disaster cases, tragic fires usually take place in midnight, when people are seldom in temples. Due to the rare casualties, the hazard index of life was ignored. The temperature $260^{\circ} \mathrm{C}$ was defined as the hazard heat value for construction. Simulation situations (Table 3) compared different safety distances $(50 \mathrm{~cm}, 80 \mathrm{~cm}$, and $100 \mathrm{~cm})$ as well as different ignition locations.

Table3. Differently safety distance and fire source size in simulation.

\begin{tabular}{|c|c|c|}
\hline safety distance & fire source size & ignition location \\
\hline $50 \mathrm{~cm}$ & $1 \mathrm{MW}$ & near left residence \\
\hline $50 \mathrm{~cm}$ & $1 \mathrm{MW}$ & far from residence \\
\hline $80 \mathrm{~cm}$ & $1 \mathrm{MW}$ & far from residence \\
\hline $100 \mathrm{~cm}$ & $1 \mathrm{MW}$ & far from residence \\
\hline
\end{tabular}

\subsection{Simulation Results}

The comparison of the situations with different safety distances and ignition locations is shown in Figure7.The result shows that:

1. In the initial stage of simulation, the scenario with $50 \mathrm{~cm}$ safety distance and an ignition location far from residence has higher value of heat release rate in the period from 0 to 180seconds.

2. No matter what the distance between left residence and vendors is, heat release rates are similar, except the situation that has $50 \mathrm{~cm}$ safety distance and an ignition location far from residence.

3. In the comparison of $80 \mathrm{~cm}$ and $100 \mathrm{~cm}$ safety distances, the fire growing and heat release rates are stable in room space, and the highest value is about $120 \mathrm{MW}$.

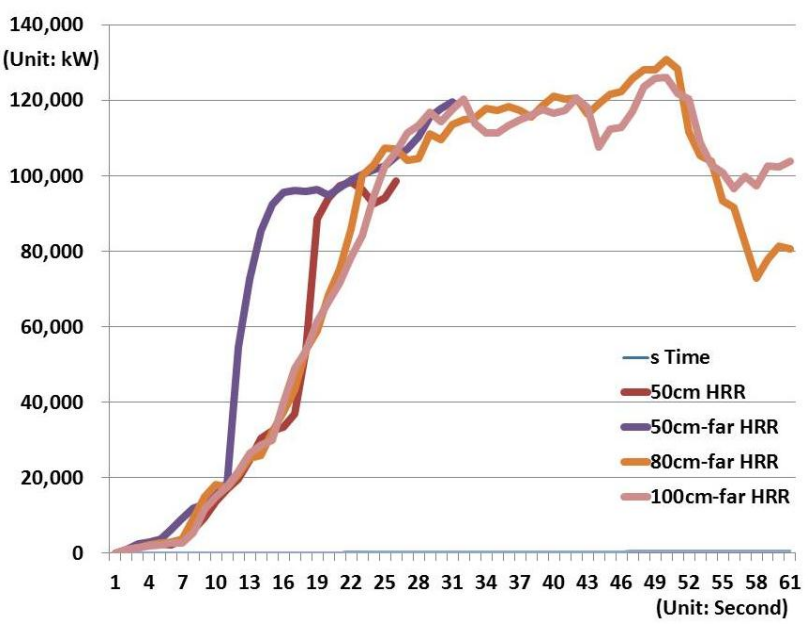

Figure7. The simulation results of heat release rate in different safety distances.

With the same combustibles and setting parameters, we found that the temperature in space complies with the reserved safety distances. As the following figures shows, with safety 
distances of $80 \mathrm{~cm}$ and $100 \mathrm{~cm}$, the interior temperature hardly rise. Figure 8 shows that the temperature rise more quickly in situations with the safety distance of $50 \mathrm{~cm}$ and fire starting from the left residence. No matter where fire location is, the temperature peak value all reach about $910^{\circ} \mathrm{C}$. At the initial stage, the temperature in nearby residence with of $50 \mathrm{~cm}$ safety distance rises suddenly at 180 seconds; another situation (far from residence) rises at 110 seconds.

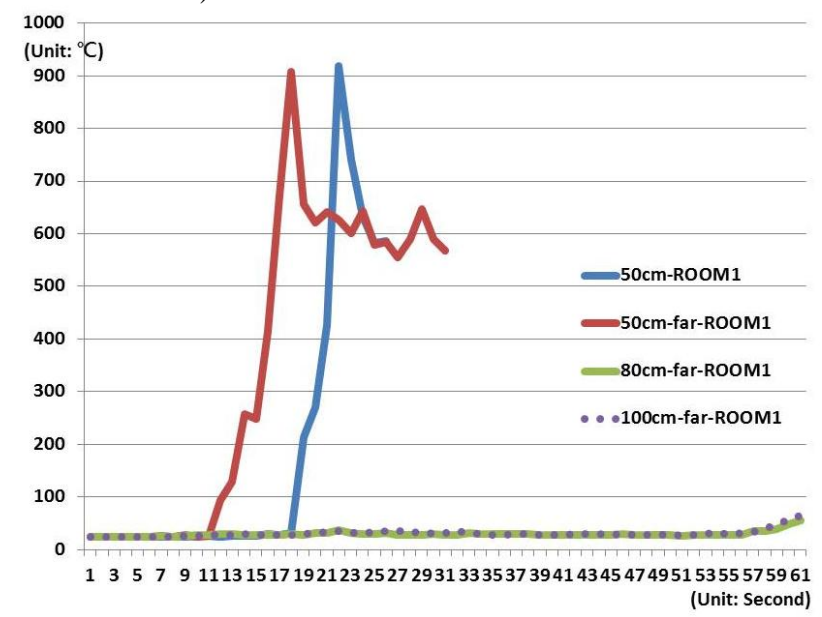

Figure8. Temperature variation occurred in the first room of the left residence.

Regarding the room directly affected by heat radiation, the simulation results presents that the room temperature grows up quickly to reach the flashover temperature (about $600^{\circ} \mathrm{C}$ ) from 0 to 110 seconds in the case with $50 \mathrm{~cm}$ safety distance. However, the room temperature climbs smoothly in the case with $80 \mathrm{~cm}$ safety distance, in which after 10 minutes, the room temperature is only about $190^{\circ} \mathrm{C}$, as shown in Figure9.

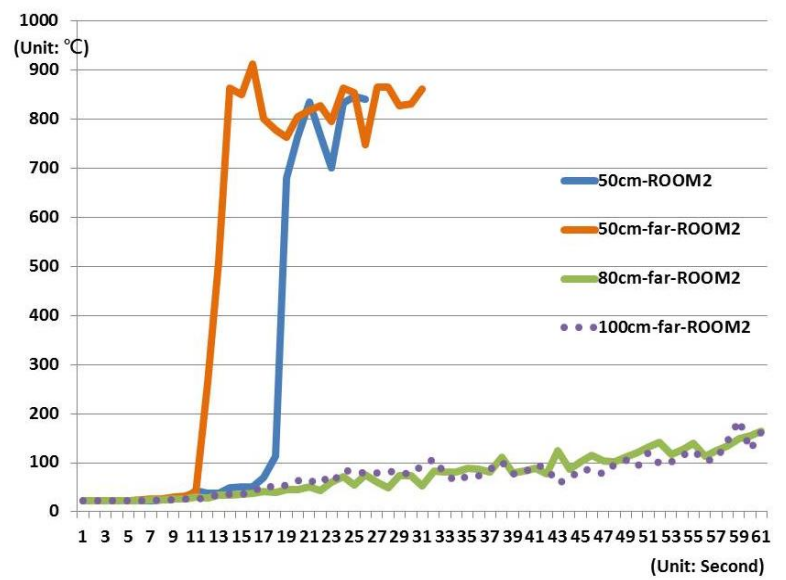

Figure9. Temperature variation occurred in the second room of the left residence.

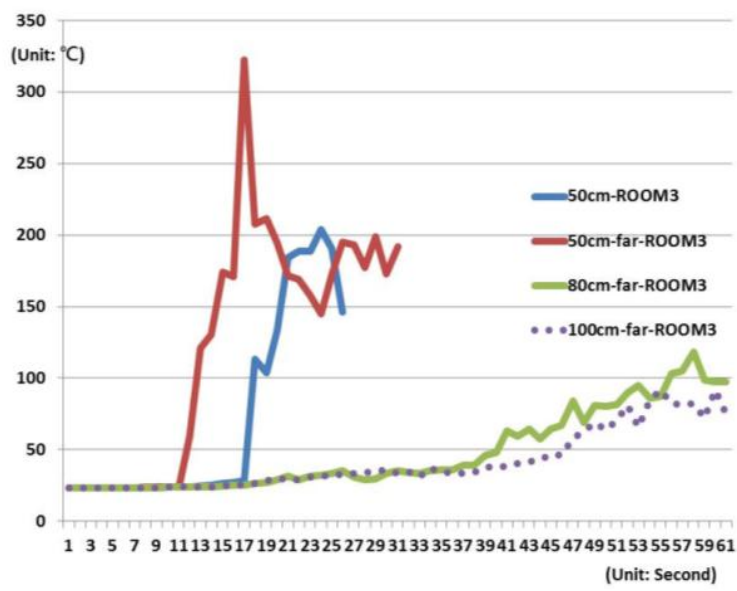

Figure10. Temperature variation occurred in the third room of the left residence.

The differences between the first and the third rooms is the amount of combustibles. The first room is unequipped, but the third room is full of papers and next to the vendors' wall. Therefore, in the third room, the internal temperature continues to reach the harmful value for wooden construction in the case with $50 \mathrm{~cm}$ safety distance. But despite the room full of combustibles, if the safety distance is above with $80 \mathrm{~cm}$, the room temperature raises up to $120^{\circ} \mathrm{C}$ at most, as shown in Figure10.

\section{CONCLUSIONS AND SUGGESTIONS}

\subsection{Discussion and Conclusion}

Based on the simulation and verification of different scenarios, we arrive at the following conclusions:

1. The simulation results showed that, $80 \mathrm{~cm}$ safety distance, which means fire is located far from the left residence, can prevent indirect radiant heat and fire spread.

2. The response measure in the initial 110 to 180 seconds with $50 \mathrm{~cm}$ safety distance should be taken, in order to prevent the room temperature increased by direct heat radiation and to reduce building's vulnerability.

3. Internal combustibles and safety distance are the key factors of fire spread. With $80 \mathrm{~cm}$ safety distance, the initial temperature in an unequipped room could maintain or increase slowly. On the other hand, the temperature in rooms with combustibles rises gradually.

\subsection{Suggestion and Countermeasure}

The simulation results suggest the following countermeasures:

1. Internal configuration should be strictly considered. In the management measure, the temple should avoid storing flammable items near to the fire risks area, especially in the vicinity of the open windows.

2. The items, such as the canvas above vendors, near cultural heritages and historical buildings may spread fire and therefore should be reduced.

3. Easy access and operation of the fire extinguishing equipment, such as simplified fire hydrant for one person operation, is a vital step in the initial response procedure. Without that, fire would be uncontrolled and extending. The combination of the early-phase detection, the local inhabitants, and the promotion of composing mutual- 
support group, can strengthen disaster resilience of the whole historic district.

\section{ACKNOWLEDGEMENTS}

We would like to thank Ministry of Science and Technology in Taiwan for funding this integrated research project: A study on Fire Resilience Model of the Historic District, 2014-2015.

\section{REFERENCES}

Andrew Croft, 2013, Assessment of Heritage at Risk from Environmental Threat- KEY MESSAGES REPORT, United Kingdom, Atkins Heritage and Historic Buildings and Monuments Commission for England.

Chen Chao-Jung, 2012, An Analytical Study on the Specified Area of Monuments Definition According to the Cultural Heritage Preservation Act, Journal of Cultural Property Conservation, 20, pp.5-26.

Chen Hai-Shu, 2009, The Necessity and Strategies of Fire Prevention Practice for Historical Buildings, Journal of Cultural Property Conservation, 9, pp. 5-12.

Chen Jui-Ling, Wen I-Jyh, 2012, A Study on Fire Risk Assessment of Monument and Historic Buildings in Taiwan, Taipei, Research paper of Architecture and Building Research Institute.

Chien Shen-Wen, 2010, A Study on Disaster Risk Assessment and Mitigation Plan for Cultural Heritage(1), National Science Councilproject, NSC99-2625-M015-002

Chien Shen-Wen, 2011, National Taiwan Museum, Fire Safety Assessment and Response Measures, Journal of Cultural Property Conservation, 17, pp. 21-30.

Chien Shen-Wen, 2013, Disaster Assessment Technique and Case Study for Taiwan's Heritage, Journal of Disaster Mitigation for Historical Cities, 7, Japan, pp. 257-264.

Chien Shen-Wen, 2014, An Integrated Study on Disaster Prevention for Cultural Heritages with Fire Risk as an Example, Journal of Disaster Management,3(1),Taiwan, pp. 1-24.
United Nations Education Scientific and Cultural Organization, 2009, Disaster Risk Management of Cultural Heritage, Proceedings of the $4^{\text {th }}$ International Training Course on Disaster Risk Management of Cultural Heritage, Kyoto and Kathmandu.

Dougal Drysdale, 2011, An Introduction to Fire Dynamics, $3^{\text {rd }}$, John Wiley \& Sons Ltd, Chichester, United Kingdom, doi: 10.1002/9781119975465.

Hasemi Yuuji, 2013, Prospects of fire safety measures in cultural heritage buildings, Journal of Japan Association for Fire Science and Engineering, Japan, 63(6).

Kevin McGrattan et al., 2013, Fire Dynamics Simulator User's Guide $6^{\text {th }}$, National Institute of Standards and Technology.

Rohit Jigyasu, Vanicka Arora, 2014, Disaster Risk Management of Cultural Heritage in Urban Areas- The Training Guide, UNESCO, Ritsumeikan University and ICCROM, ISBN: 978-4-9907044-0-7,

Shao Pei-Chun, 2010, Fire-Safety Strategy for Urban Traditional Region: The Case of Provintia (Chih-Kan) Cultural Zone in Tainan City, Journal of Urbanology, 1(1), pp. 57-84

Shen Tzu-Sheng, 2013, Fire Safety Analysis on the historical Heritages with Southern Fukien Style Example on Tainan Grand Matsu Temple in Taiwan, Journal of Disaster Mitigation for Historical Cities, 7 , pp. 249-256

Susan L. Cutter et al., 2003, Social Vulnerability to Environmental Hazards, Social Science Quarterly , 84, pp. 242-261.

UNESCO, 2011, New life for historic cities: The Historic Urban Landscape Approach Explained, 36th session of UNESCO's General Conference.

Wang Song-Yon, 2007, Fire Behavior and Fire Protection Procedures for Wooden Historical Buildings, Journal of Cultural Property Conservation, 1(1), Taiwan, pp. 18-26. 